\title{
CENÁRIO ECONÔMICO E POLÍTICO MUNDIAL E TENSÕES CONTEMPORÂNEAS NA EDUCAÇÃO: NARRATIVAS E CONCEPÇÕES DE PESQUISADORES NO VI SEMINÁRIO DA EDUCAÇÃO BRASILEIRA
}

\author{
Maria Vieira Silva ${ }^{1}$
}

\begin{abstract}
RESUMO: A educação pública tem sido tangenciada, de forma contígua, por graves questóes contemporâneas, as quais nos impóem a necessidade de adensar análises sobre as atuais bases societais, as reconfiguraçóes das instituiçóes políticas, as mutaçóes no mundo do trabalho e as apropriaçóes do espaço público. No presente texto, colocaremos em relevo importantes contributos do Centro de Estudos Educação e Sociedade (CEDES) ao debate das referidas questóes, mediante temáticas abordadas por expressivos pesquisadores durante o VI Seminário da Educaçáo Brasileira. Realizaremos o encadeamento de teses apresentadas nesse evento por meio de nexos temáticos agrupados em dois eixos: "Metamorfoses no mundo do trabalho e suas correlaçóes com o capitalismo organizado" e "As recentes mutaçóes do Estado, a ascensão dos paradigmas mercantis e suas consequências para o campo da educação".
\end{abstract}

Palavras-chave: Seminário da Educação Brasileira. Reconfiguração do Estado. Educação pública.

\section{WORLD ECONOMIC AND POLITICAL SCENARIO AND CONTEMPORARY TENSIONS IN EDUCATION: NARRATIVES AND CONCEPTIONS OF RESEARCHERS IN THE VI SEMINAR ON BRAZILIAN EDUCATION}

\begin{abstract}
Public education has been continuously affected by serious contemporary issues, which impose on us the need of broadening analyses of current societal bases, the reconfiguration of political institutions, the changes in the world of work and the appropriation of public space. In this article, we will highlight important contributions of the Center for Studies in Education and Society (CEDES) to the debate on these issues, through topics addressed by significant researchers during the VI Brazilian Education Seminar. We will connect the thesis
\end{abstract}

\footnotetext{
${ }^{1}$ Universidade Federal de Uberlândia - Uberlândia (MG), Brasil. E-mail: mvieiraufu@gmail.com
} DOI: 10.1590/ES0101-73302019224315 
presented in this event through thematic links grouped into two central lines: "Metamorphoses in the world of work and their correlations with organized capitalism" and "The recent mutations of the State, the rise of market paradigms and their consequences for the field of education".

Keywords: Brazilian Education Seminar. Reconfiguration of the State. Public education.

\title{
ESCENARIO ECONÓMICO Y POLÍTICO MUNDIAL Y TENSIONES CONTEMPORÁNEAS EN LA EDUCACIÓN: NARRATIVAS Y CONCEPCIONES DE INVESTIGADORES EN EL VI SEMINARIO BRASILEÑO DE EDUCACIÓN
}

RESUMEN: La educación pública ha sido dejada de lado, de forma progresiva, por graves problemas contemporáneos, los cuales nos exigen la necesidad de profundizar el análisis de las actuales bases sociales, las reconfiguraciones de las instituciones políticas, los cambios en el mundo del trabajo y las apropiaciones del espacio público. En el presente artículo, destacaremos importantes aportes del Centro de Estudios Educación y Sociedad (CEDES) al debate de estos temas, a través de temas abordados por importantes investigadores durante el VI Seminario de Educación Brasileña. Realizaremos el encadenamiento de las tesis presentadas en este evento por medio de enlaces temáticos agrupados en dos ejes: "Metamorfosis en el mundo del trabajo y sus correlaciones con el capitalismo organizado" y "Las recientes mutaciones del Estado, el ascenso de los paradigmas mercantiles y sus consecuencias para el campo de la educación".

Palabras clave: Seminario de Educación Brasileña. Reconfiguración del Estado. Educación pública.

\section{Introdução}

\begin{abstract}
A ascensão e a consolidação das políticas neoliberais no tempo presente têm produzido efeitos nefastos sobre a justiça social, a dignidade humana e as parcas conquistas da cidadania. Tais processos têm sido marcados por um mosaico social, com efemérides que se complementam ou se justapóem, tais como: reforma do Estado; desemprego estrutural; transformaçóes no mundo do trabalho aliadas aos diferentes mecanismos de precarização das relaçôes de trabalho; atomização dos trabalhadores; enfraquecimento das instâncias coletivas; força e volatilidade dos mercados financeiros. Os impasses contemporâneos produzem efeitos também sobre dimensóes subjetivas e dinâmicas identitárias, ensejando o medo, a insegurança e a intolerância em suas múltiplas manifestações: machismo, misoginia, racismo, homofobia.
\end{abstract}


Esse complexo panorama social, econômico e político incide sobre a base de representação do Estado, pois essas novas dinâmicas se expandem de forma crescente, sobretudo durante as últimas três décadas, contribuindo para o arrefecimento dos espaços coletivos e participativos em todas as instâncias do tecido social, o descrédito de tudo que é público e a sacralização do mercado mediante o arrefecimento de políticas sociais e a instauração da barbárie que se substantiva no tecido social, como o desemprego estrutural, a fome, a criminalidade, a violência e a abissal desigualdade de renda.

É nesta conjuntura que o Centro de Estudos Educação e Sociedade (CEDES) tem envidado esforços para analisar as multifacetadas feiçóes do capitalismo contemporâneo, mediante conexôes entre as dinâmicas societais e o campo da educação, contribuindo com a difusão da produção do conhecimento, também mediante a realização de seminários. Com efeito, em 1979, foi realizado o I Seminário da Educação Brasileira (SEB), na Universidade Estadual de Campinas (Unicamp). Em 2009, o SEB retoma sua periodicidade e se dedica a promover instigantes reflexôes e debates sobre temáticas candentes do campo educacional envolvendo pesquisadores de diferentes instituiçóes do país e do exterior. Em sua última edição, realizada entre os dias 10 e 12 de dezembro de 2018, a temática que ancorou o VI SEB foi Cenário econômico e político mundial e tensóes contemporâneas na educação. Os debates foram alicerçados em graves questôes contemporâneas, as quais nos impóem a necessidade de repensar as bases do tipo de sociedade que estamos vivendo, a desagregação das sociedades política e civil, as novas reconfigurações das instituições políticas e a apropriação do espaço público.

Nesse sentido, o presente texto teve como objetivo colocar em relevo as reflexões e os debates desencadeados por ocasiāo do referido Seminário, como forma de registro desse importante evento acadêmico, visando ensejar reflexóes, promover diálogos indagativos sobre as abordagens dos conferencistas e painelistas, para uma percepção, ainda que parcial e concisa, da memória do SEB. As acepçóes e os significados atribuídos à memória indicam a preservação de recordações e apontam também para um movimento de vida. Mnemosyne, deusa que personifica a memória, filha de Urano e Gaia, representa, grosso modo, a proteção do esquecimento. Assim pensando, de certo modo, a memória pode também nos preservar da morte pelo esquecimento. De acordo com Chauí (1996, p. 125-130), "a memória é uma evocação do passado. É a capacidade humana de reter e guardar o tempo que se foi, salvando-o da perda total, [...] é uma atualização do passado ou a presentificação do passado e é também registro do presente para que permaneça como lembrança".

Destarte, os registros aqui dispostos neste texto-memorial do VI SEB remontam às teses e aos fragmentos das exposiçôes de renomados pesquisadores e expressivos intelectuais da área de humanidades do Brasil, de Portugal e 
da França. Sob tal perspectiva, o presente texto apresenta abordagens reflexivas do cenário político e econômico em suas conexôes com o campo educacional mediante imbricadas relaçóes que se plasmam em um substrato material da vida social.

\section{Terreno e atmosfera política no VI Seminário da Educação Brasileira}

O VI SEB foi realizado durante o último mês do Governo Temer, em um momento em que ainda estávamos sob o impacto da eleição de Jair Bolsonaro (Partido Social Liberal — PSL) à presidência da República.

Sem embargo, a atmosfera política dos conferencistas e participantes do referido evento encontrava-se ainda bastante impactada pelas distopias e pelas indignaçóes diante dos acintes à jovem e frágil democracia brasileira, aos recorrentes processos de perda de direitos sociais instaurados durante o Governo Temer e pelos horizontes de agudização do declínio do Estado Democrático de Direito, na porvindoura gestão de Jair Bolsonaro.

A destituição da então Presidenta Dilma Rousseff, em 31 de agosto de 2016, ocasionou a ascensão do vice-presidente Michel Temer ao cargo de Presidente da República, o qual, durante um bom período de seu governo, contou com o apoio contundente de uma expressiva base aliada de partidos políticos e parlamentares nas esferas legislativas (Câmara Federal e Senado), como também com a fidelidade política do presidente da Câmara Federal — Eduardo Cunha (Partido do Movimento Democrático Brasileiro - PMDB-RJ), que, após seu afastamento pelo Supremo Tribunal Federal e cassação do mandato por quebra de decoro, pela Câmara Federal, em 12 de setembro de 2016, foi substituído por Rodrigo Maia (Democratas - DEM-RJ) - e do presidente do Senado - Renan Calheiros (PMDB-AL), que, ao fim da vigência do cargo, em $1^{\circ}$ de fevereiro de 2017, foi substituído por Eunício Oliveira (PMDB-CE).

O clima político favorável ao Executivo Federal possibilitou a indução de medidas provisórias, Projetos de Emendas Constitucionais e Decretos pelo Executivo, o que foi apoiado e fortemente defendido pela ampla maioria dos deputados e senadores, além do amplo time de ministros, grande mídia e até membros do poder judiciário, em pronunciamentos, dentro e fora dos autos, inequívocos quanto à orientação político-partidária, ensejando verdadeiras ofensivas aos direitos sociais e aos direitos trabalhistas, entre as quais destacamos: Reforma Trabalhista1; Lei de Terceirizações; Reforma Previdenciária, Proposta de Emenda Constitucional no 241/55 (conhecida como PEC do Teto dos Gastos), Medida Provisória no 246 e várias reformas e medidas arbitrárias em vários campos. Tais dispositivos político-jurídicos são indicadores de um quadro grave de ruptura democrática no país, com desdobramentos sem pre- 
cedentes ao colocarem em risco a cidadania, os direitos sociais e educacionais arduamente conquistados.

Sem embargo, em um conturbado e dividido contexto político, e em meio ao esgarçamento do Governo Temer e à expressiva rejeição aos partidos de esquerda, presenciamos a ascensão da extrema direita no cenário político brasileiro. Com pautas conservadoras e posições extremadas, Jair Bolsonaro foi vencedor das eleiçóes presidenciais de 2018, com discursos agressivos, autoproclamado restaurador da ordem perdida e combatente do suposto regime socialista instaurado no Brasil. Compóe também sua retórica o retorno das forças armadas à frente da arena política, o antifeminismo, o antissocialismo, além de expressóes homofóbicas e racistas presentes em seus discursos e dos adeptos de seu perfil político, ensejando o ascenso de um cariz contemporâneo do fascismo na realidade tupiniquim.

A conjuntura política descrita nesta seção - ainda que de forma sumária - é emblemática da fragilidade da democracia na história da política brasileira. Discursos oficiais e práticas políticas estabelecem quem está no centro e quem ocupa as posiçóes marginais, quem se estabelece nas arenas políticas e quem é ocultado nesses espaços. É nessa realidade, com todas as suas complexidades e contradiçôes, que os conferencistas do VI SEB desenvolveram densas e consistentes reflexões, mediante nexos entre as determinaçóes macrossociais no espaço-tempo-mundo e as singularidades políticas que se processam na realidade brasileira. Sob a temática geral Cenário econômico e político mundial e tensões contemporâneas na educação, as conferências e os painéis tangenciaram temas que podem ser agregados em dois grandes eixos: "Metamorfoses no mundo do trabalho e suas correlaçóes com o capitalismo organizado" e "As recentes mutações do Estado, a ascensão dos paradigmas mercantis e suas consequências para o campo da educação", conforme abordaremos na seção que se segue.

\section{Metamorfoses no mundo do trabalho e suas correlações com o capitalismo organizado}

As sínteses analíticas presentes na conferência de abertura do VI SEB intitulada Cenário Econômico Político Mundial, desenvolvidas pelo professor Reginaldo Moraes, transversalizaram os dois eixos supramencionados a partir de perspectivas históricas sobre a concepção de Estado em sentido lato. A partir de inflexōes sobre os sentidos da palavra "cenário", Moraes (2018) ressalta que o uso ali empregado tem a conotação de uma metáfora, uma vez que a acepção dela remete a um ambiente construído e adornado para o desenvolvimento de uma trama teatral, aspecto que guarda diferenças em relação ao âmbito político. Assim, afirma que o cenário em uma peça de teatro é um espaço um tanto 
quanto inerte, no qual os personagens executam um script que alguém elaborou. Diferentemente dessa dimensão, no "cenário" político os sujeitos atuam sobre seu destino, mudam cenas, elaboram falas e reagem; assim, refletem e intervêm sobre a realidade.

Tendo como referência os mencionados discernimentos e limites da sintaxe da palavra "cenário", o conferencista ressalta que o conceito de Estado é polissêmico e sofre mutações de acordo com as múltiplas determinações dos cenários políticos. Sob o prisma dos nexos estabelecidos entre Estado e política, Moraes (2018) retoma, sumariamente, conceitos clássicos e distintos: para Lênin, Estado é um conjunto de prisões, tribunais, exército, polícia, aparato repressivo. Sob a perspectiva liberal weberiana, o Estado é um monopólio da coerção física legítima de um determinado território, ou seja, ambos os autores concebem o Estado como aparato repressivo. Ao se remeter a tais concepçóes, Moraes (2018) assevera que elas são produtos da sociedade em certa fase do seu desenvolvimento. Com efeito, as conceituações e as composições do Estado vão se metamorfoseando, sendo sua atual estrutura extremamente complexa. Alguns eventos foram determinantes para mudanças e rupturas para a criação do Estado moderno, como a Segunda Guerra Mundial, com controle bipolar.

Destarte, no período pós-Segunda Guerra, o Estado amplia seu espaço de intervenção mediante agências reguladoras, transforma-se em uma arena em disputa por ampliaçôes de poder e intensifica as conexôes com setores e agências mercadológicas visando à regulação das relaçôes entre os estados-naçôes. Após os acordos e os compromissos de Bretton Woods, foram criadas instituiçóes financeiras mundiais que se encarregariam de dar o sustento necessário aos modelos que estavam sendo adotados, tais como o Acordo Geral de Tarifas e Livre Comércio (GATT); a Organização Internacional do Comércio (OIC); o Fundo Monetário Internacional (FMI); e o Banco Mundial.

Moraes (2018), após discorrer sobre o desenho do mundo no pós-guerra, apresenta reflexōes sobre algumas transições no formato do Estado, mediante um histórico de sua evolução. Com efeito, aborda dimensôes concernentes ao seu papel como agente fomentador do desenvolvimento econômico, sob a lógica do capital na condição de regulador direto ou indireto de direitos sociais, ensejada pelo formato do Welfare State, ou Estado do Bem-Estar social. Destaca ainda a atuação do Estado em favor da política econômica à custa da política social nos anos 1970, alicerçado em pilares do programa neoliberal, com desdobramentos como: crescimento das desigualdades; mudanças rápidas e crescimento precário; redução do Estado como provedor de bens e serviços e como regulador e ascensão dos processos de privatização; pressão sobre políticas públicas, como saúde, educação e previdência e trabalho pulverizado. O último aspecto elencado ensejou a segmentaçáo e a pulverização dos trabalhadores, ao promover um deslocamento 
do centro da cadeia produtiva para unidades periféricas, provocando a precarização das relaçóes e condiçóes de trabalho, ocasionando a redução de empregos e sérios danos à base de representaçáo dos sindicatos, e contribuindo para a flexibilização ou extinção dos direitos sociais conquistados pelos trabalhadores, mediante a reengenharia da reestruturaçáo produtiva.

No âmbito do Simpósio As recentes transformaçōes no mundo do trabalho e suas consequências para o campo da educaçâo, Linhart (2018), a partir de contributos da sociologia do trabalho, coloca em relevo remodelações gestoriais presentes no processo de reestruturação produtiva por meio de discursos disseminados pelos gestores empresariais contemporâneos. Assevera que essa ofensiva, no atual contexto, é uma continuidade da ideologia tayloriana, ao praticar o velho princípio de captação dos saberes por via de sua transferência para softwares, produzindo estratégias para tornar obsoletas a experiência profissional e as competências individuais e coletivas dos assalariados mediante uma política de mudanças constantes. Afirma ainda que, no bojo desse processo, esses discursos gestoriais são travestidos de uma perspectiva positiva da "moderna" forma de gestão empresarial ao demonstrar preocupaçáo com a qualidade do bem-estar do trabalhador, mas tais discursos contrastam com o aumento, sem precedentes nas últimas décadas, do sentimento de mal-estar e de sofrimento daqueles que vivem do trabalho.

Dialogando com as abordagens sociológicas de Linhart (2018), o economista Krein (2018) desenvolve análises sobre as mudanças no mundo do trabalho ensejadas pelo capitalismo contemporâneo com desdobramentos no sistema de proteçáo social. Tendo como referência as mutaçóes na esfera macrossocial, Krein (2018) enfoca a reconfiguração progressiva da classe trabalhadora e seu apogeu, na realidade brasileira, materializado na Lei da Reforma Trabalhista (Lei no 13. 467/17), com impactos negativos sobre a constituição dos fundos públicos para o financiamento da política social, especialmente referente à seguridade.

Argumenta ainda que a flexibilidade nas relações de produção é sinônimo da liberdade de o capital gerir o trabalho de acordo com suas conveniências, submetendo o trabalhador a uma maior insegurança ao ampliar a liberdade do empregador em determinar as condiçôes de contratação, o uso da mão de obra e a remuneração do trabalho. Com efeito, no bojo das metamorfoses do mundo do trabalho, assume centralidade o processo de terceirização, ao permitir a sua utilização de forma indistinta, inclusive em atividade-fim e em qualquer setor. Em consonância com as mudanças no universo laboral enfocadas por Linhart (2018), as abordagens de Krein (2018) evidenciam os atuais formatos de precarizaçáo do trabalho, mediante algumas modalidades, tais como o contrato temporário, o trabalho autônomo, a "pejotização" e a cooperativa de trabalho. Nesse processo, os empregadores contam com um leque de contrataçóes atípicas, temporárias e mais 
precárias, como a ampliação do contrato a tempo parcial para até 32 horas semanais, admitindo horas extraordinárias; a introdução do contrato intermitente, que proporciona liberdade para a empresa contratar somente pela jornada trabalha$\mathrm{da}$, ocasionando descontinuidades laborais e vulnerabilidade para o trabalhador, coetaneamente à perda de direitos e à diminuição da proteção social. Os efeitos da reforma trabalhista são também nefastos para as organizações sindicais em decorrência da ascendência de organizaçóes descentralizadas e articuladas com os interesses das empresas.

Sob tal perspectiva, a acepção de "modernização das relações de trabalho" precisa ser relativizada, uma vez que as atuais mudanças estão mais em consonância com o padrão privado de regulação do trabalho do século XIX. As análises em tela evidenciam que as atuais reconfiguraçóes das relaçóes de trabalho ensejam ambientes com maior pressão sobre os trabalhadores, mediante o propósito de forçá-los a aceitar um padrão de regulação do trabalho flexibilizado, instável e precário, com efeitos perversos sobre a proteção social dos assalariados. Krein (2018) ressalta ainda que, mesmo com uma ampla legislação trabalhista na realidade brasileira, as condições objetivas do mercado de trabalho sempre foram muito desaforáveis para os trabalhadores, e a atual reforma trabalhista significa um retrocesso social ainda maior e a agudização de processos de exploração da mão de obra.

As reflexões de Paro (2018), no âmbito do Simpósio Humanização e Mercantilização: tensóes na organização escolar e na formação do profissional da educação, possibilitam também reflexóes concernentes ao mundo do trabalho, no entanto o foco de sua exposição incidiu sobre o trabalho docente e a especificidade da educação e da natureza do trabalho pedagógico. Para tanto, recupera a categoria marxiana trabalho como fundante para a compreensão das dimensóes ontológicas, na constituição do homem como sujeito histórico e na dimensão epistemológica no processo de produção do conhecimento. Com base em incursóes teóricas sobre conceitos correlatos à categoria trabalho, aborda ainda "força de trabalho", "mais-valia", "produção material e produção não material", "trabalho concreto e trabalho abstrato". Tais conceituaçóes suscitam importantes reflexóes acerca da natureza identitária do docente e sua vinculação ao trabalho produtivo ou improdutivo. As contribuiçóes de Paro (2018), ao colocar esse debate em pauta, possibilitam importantes contributos para formulaçóes referentes aos conceitos de "proletarização docente" e "precarização do trabalho docente", uma vez que esse é um campo com dissensos hermenêuticos acirrados, sendo que muitos pesquisadores entendem que as categorias marxistas não são adequadas para a compreensão das especificidades do trabalho docente, uma vez que, na atividade de ensino, os processos de trabalho não têm como finalidade direta a criação de valor, distinguindo-se do processo fabril, sobretudo no que tange à produção de mais-valia. 
Freitas (2018), ao tecer críticas às propostas de governo de Jair Bolsonaro para o mandato 2019-2022, afirma que os princípios estão alicerçados no conservadorismo associado ao liberalismo econômico, aos grupos militares e à extrema direita. Segundo o conferencista, a eleição de Bolsonaro é emblemática de como a democracia brasileira foi aprisionada e se tornou refém de uma agenda neoliberal. Para analisar o ascenso de políticas neoconservadoras, em escala mundial, Freitas (2018) remete às teses de Nancy MacLean, presentes no livro Democracy in Chains: the deep history of the radical right's stealth plan for America (Democracia Aprisionada: a história profunda do plano oculto da direita para a América). Trata-se de teorizaçôes sistematizadas a partir de documentos encontrados acidentalmente pela professora em uma casa de madeira abandonada no campus da Universidade George Mason, em Virgínia, Estados Unidos. Entre os documentos encontrados, MacLean disponibiliza o conteúdo das cartas confidenciais de James McGill Buchanan, cujo conteúdo versava sobre milhóes de dólares transferidos para a universidade pelo bilionário Charles Koch. $\mathrm{O}$ teor dos referidos documentos evidencia como Buchanan desenvolveu proposiçóes e planos em parceria com multimilionários e institutos fundados por eles, cuja base é a supressão da democracia em favor de grupos altamente privilegiados que entram em cena no processo de redefinição da política, em uma realidade para além dos Estados Unidos. Buchanan ainda defende que as garantias para o livre mercado deveriam ser incluídas nas constituiçóes nacionais de forma a se tornarem praticamente irrevogáveis mesmo que por caminhos que pudessem significar uma ruptura com as teses da democracia liberal (apud FREITAS, 2018).

Com efeito, instaura-se uma ditadura do mercado sobre o cidadáo, com o objetivo de impor um conjunto de proposituras articuladas em torno do que se chama a "nova direita radical", mediante a liberdade sem travas do mercado. Sob tal prisma, assegura o conferencista, "liberdade" é igual a "capitalismo sem restriçōes", sem interferência de governos. Lembra ainda que o neoliberalismo fundou a reforma empresarial da educação em 1955 com a tese dos vouchers e do livre mercado na área da educação. Destarte, apesar de suas características híbridas, as origens do movimento da reforma empresarial remontam ao nascimento de uma "nova direita", que procurou combinar o liberalismo econômico com autoritarismo social. No atual contexto, a reforma empresarial da educação se desenvolve em sua versão mais expressiva, mediante múltiplos mecanismos, tais como o sistema de vouchers, a política de responsabilização baseada em testes, criando um "vetor de privatização" no âmbito educacional.

Na próxima seção, apresentaremos algumas teses desenvolvidas pelos conferencistas no âmbito do VI SEB concernentes ao incremento da intensificação da lógica privatista no campo da educação e suas implicaçóes para o arrefecimento das políticas sociais e para a garantia do direito à educação. 


\section{As recentes mutações do Estado, a ascensão dos paradigmas mercantis e suas consequências para o campo da educação}

As análises de distintos cenários políticos que ensejaram mutações no Estado, presentes na conferência de abertura do VI SEB, proporcionaram-nos nexos importantes com os simpósios que se seguiram, uma vez que delinearam um plano de fundo importante para o complexo exercício de estabelecer relaçóes entre as determinaçóes macrossociais e as regularidades que se processam no plano micro, por meio da estratégia analítica e interpretativa da mútua-determinação entre a superestrutura e a base material.

Assim, o simpósio intitulado Reformas conservadoras e a 'nova educação': orientaçóes hegemônicas em debate teve como foco as reformas conservadoras em curso no cenário das políticas públicas no campo da educaçáo, mediante análises críticas sobre os pressupostos político-educacionais subjacentes à "nova educação" e seus pressupostos hegemônicos. Os expositores foram unânimes ao reconhecer que vivemos uma profunda crise da democracia na realidade brasileira, em razão da ascensão de um projeto político que representa uma ofensiva às conquistas sociais, pautada em uma agenda política excludente e autoritária com medidas de austeridade dos gastos sociais, e da liberalização dos fundos públicos para socorrer os negócios do capital.

Sob tal perspectiva, Leher (2018) destaca que a atual conjuntura denota uma correlação de força muito negativa para o país, em razão de derrotas ensejadas por mudanças constitucionais deletérias ao papel social do Estado e um agudo processo de mercantilização da educação. O conferencista menciona as mudanças no mundo do trabalho e suas derivaçóes, como a reforma trabalhista; e a precarização do trabalho docente, expresso, por exemplo, no percentual de $40 \%$ de docentes sem contrato regular de trabalho. Além disso, remete-se às mudanças estruturais no âmbito dos poderes institucionais mediante uma complexa imbricação entre as esferas Executiva e Judiciária, cujo alcance se traduz em aparelhamento de polícias nos campi universitários, denúncias ao Ministério Público relativas ao teor de investigaçóes de históricos e renomados pesquisadores, entre outras açóes nocivas à autonomia universitária e à liberdade de cátedra.

Leher (2018) referencia-se no conceito de bloco de poder de Poulantzas para apresentar sua tese de Estado capitalista como uma "relação". Sumariamente, de acordo com Poulantzas (1985, p. 162), o "Estado concentra não apenas a relação de força entre frações do bloco no poder, mas também a relação de forças entre estas e as classes dominadas". Assim, o conceito de bloco no poder pode ser concebido como uma unidade contraditória entre distintas classes e/ou fraçóes de classes, sob a hegemonia no seu interior de uma dessas fraçóes ou classes, em suas relações 
com o Estado capitalista. Sob tal prisma, Leher (2018) ressalta a coalizão entre setores governamentais e o Movimento Todos pela Educação, além de fundaçóes e outros grupos empresariais que operam no campo educativo, legitimados por um discurso de ausência de qualidade da escola pública e da suposta necessidade de convocar a sociedade civil para resgatar a qualidade educacional. Com efeito, assevera que a educação passa a ser ressignificada para difundir competências e mensurar desempenhos por meio de um sofisticado aparato avaliativo aliado à expropriaçáo dos conhecimentos de professores. Nesse sentido, critica que o Plano Nacional de Educaçáo (PNE) priorizou a lógica das avaliaçôes meritocráticas e unilaterais, por meio do Índice de Desenvolvimento da Educação Básica (IDEB), e afirma que a atuação do capital no bloco do poder se manifesta na organização do aparato educativo, por meio do fornecimento e da organizaçáo das mediaçôes e tecnologias que chegam às escolas públicas. Leher (2018) questiona ainda: como os trabalhadores estão organizados para defender uma outra perspectiva de educação? Embora reconheça distintos processos organizativos como alternativas ao bloco hegemônico ${ }^{2}$, afirma que a ausência de uma agenda unificada para esses movimentos enseja vulnerabilidades, portanto é necessário repactuar uma agenda comum para a defesa da escola pública.

Aguiar (2018) também manifesta perplexidade perante a conjuntura política atual e seus efeitos perversos no âmbito das políticas educacionais, no entanto resgata o histórico protagonismo da sociedade civil no processo de contraposição às relações sociais hierárquicas pautadas pelo ideário hegemônico capitalista. Nesse sentido, evoca a luta dos educadores por meio da Campanha Nacional pela Escola Pública e Gratuita, ensejada pelo Fórum Nacional em Defesa da Educação Pública, no período pós-ditadura militar, e a conquista de alguns direitos educacionais consagrados na legislação, principalmente por meio do capítulo da educação na Carta Magna. Vale ressaltar que a regulamentação desse dispositivo constitucional ficou sob responsabilidade da Lei de Diretrizes e Bases da Educação Nacional (LDB - Lei no 9.394/1996), aprovada em 20 de dezembro de 1996, após oito anos de tramitação no Congresso Nacional. Essa Lei, por sua vez, foi fruto de muita polêmica e crítica por parte da sociedade civil, sobretudo de entidades que compunham o Fórum Nacional em Defesa da Escola Pública. De acordo com Aguiar (2018), a referida lei sofreu os impactos do cenário econômico e mundial a partir da reforma do Estado em curso desde o início dos anos 1990, ancorada nos princípios neoliberais e nas diretrizes dos organismos multilaterais.

Aguiar (2018) recupera ainda aspectos importantes da mobilização da sociedade civil por ocasião das Conferências Nacionais de Educação (CONAEs), as quais representam espaços fundamentais para a participação popular, mediante proposiçôes de políticas educacionais brasileiras. Precedidas pelas conferências estaduais e municipais, as CONAEs consolidaram-se como espaços democráticos e emblemáticos da luta dos educadores pela defesa da escola pública, com diretri- 
zes e estratégias de ação amplamente debatidas. No entanto, apesar dos avanços alcançados com esse processo, o autor reconhece que a máquina governamental nas gestóes do Governo Lula (2003-2006 e 2007-2011) não era composta apenas de quadros progressistas, uma vez que havia também a presença de representantes de setores conservadores, cujas posiçóes se traduziam em programas e açóes que contrapunham os movimentos progressistas. Aguiar (2018) assegura que tal aspecto ensejou tensóes e certas mutaçóes nos projetos originários das CONAEs, os quais eram encaminhados para a esfera do Executivo e depois para o Legislativo. Assim, o projeto de Lei do PNE, quando tramitou nas instâncias legislativas, incorporou várias emendas e, no que se refere às questóes curriculares, a ideia do currículo único foi incluída no texto e, posteriormente, retomada para sedimentar as Bases Nacionais Comuns Curriculares (BNCC). Ainda de acordo com a conferencista, o discurso da obrigatoriedade da BNCC pela Constituição Federal e pela LDB é falacioso. Por outro lado, a posição dos grupos progressistas reconhecia a necessidade da construção de uma Base Comum Nacional de forma dialogada com educadores, mas refutava um currículo de natureza prescritiva consoante à lógica do mercado dos livros didáticos.

Além disso, a fragmentação dos documentos curriculares entre os diferentes níveis da Educação Básica comprometeu o sentido de indissociabilidade atribuído a esse nível educacional, sendo que a aprovação da terceira versão das BNCC do ensino médio ocorreu de forma antidemocrática. Tal aprovação ocorreu mediante o alijamento crescente dos diferentes segmentos da comunidade educacional em relação à produção da última versão, que ficou sob a responsabilidade de representantes do Ministério da Educação (MEC). No decorrer desse processo, as audiências públicas tiveram a presença marcante de representantes do Movimento Escola sem Partido, aspecto que reflete seu caráter contrário ao respeito à diversidade e evidencia a concessão que o MEC tem feito ao conservadorismo no Brasil.

Dourado (2018), referenciando-se em Otávio Ianni, inicia sua exposição remetendo-se aos aspectos histórico-sociais da globalização nos processos de sociabilidades e seus alcances nos quadros sociais e mentais de referência de indivíduos e coletividades, povos, nações e nacionalidades, culturas e civilizações. Dourado (2018) afirma ainda que, nesse palco que gravita a sociedade brasileira, as reformas conservadoras se encontram no bojo das orientaçóes hegemônicas, portanto não são contraditórias aos processos de acumulação capitalista e de apropriação dos fundos públicos.

Em sua análise de conjuntura, o conferencista apoia-se em Apple (2003 apud DOURADO, 2018) ao asseverar que a ameaça aos ideais da igualdade mobiliza neoconservadores, neoliberais e populistas autoritários. Assim, realiza um mapeamento da configuração de grupos da aliança neoconservadora que têm indicado a direção das políticas educacionais. No horizonte de uma reintegração da 
educação com a plataforma econômica, tais grupos naturalizam o apartheid educacional, por meio de diferentes políticas ancoradas na lógica mercantil. Esse processo tem sido legitimado por uma produção discursiva midiática que veicula retóricas baseadas no pressuposto de que a educação não forma adequadamente para o desenvolvimento econômico e que o problema não é o financiamento da educação, mas a ineficiência na gestão dos recursos públicos.

Ainda de acordo com Dourado (2018), um vetor dessas novas finalidades políticas coloca em risco direitos historicamente conquistados, uma vez que entram em cena os reformadores empresarias e sua lógica educacional como um negócio lucrativo. São emblemáticos desse processo currículos nacionais obrigatórios pautados em testes padronizados em um sistema desconcentrado, com formatos de identidade social e narrativas de poder adversos às políticas de inclusão, uma vez que a diferença e a diversidade são incompatíveis com a base nacional comum. Paradoxalmente, a uniformização do currículo assume protagonismo nos atuais projetos de reformas educacionais, chancelada pelas BNCCs. As reflexóes de Dourado (2018) convergem com as análises de Aguiar (2018) ao criticar a participação de diversos setores que não pertencem ao campo educacional na elaboração de políticas curriculares, cujas ideologias se reverberam no mencionado documento. Ambos os pesquisadores evidenciam que a implantação da BNCC e da reforma do ensino médio está eivada de interesses políticos, relacionada às demandas econômicas.

Ao desenvolver reflexóes sobre essa complexa configuração de interesses dos agentes do capital, Dourado (2018) assegura ainda que a profunda desigualdade e as injustiças sociais demandam desafios e alternativas baseadas em políticas de Estado, em consonância com a histórica bandeira dos movimentos sociais. Destarte, no campo da educação, tais políticas de Estado devem dar suporte para a regulamentação do regime de colaboração, aspecto fundamental para uma agenda política voltada para o financiamento que possa garantir o direito à educação, com qualidade, conforme os parâmetros do Custo AlunoQualidade (CAQ).

Diante dos desafios do financiamento do sistema de ensino, essa temática também assumiu centralidade em diferentes simpósios mediante os enfoques das conferências de Alves (2018), Cara (2018) e Ximenes (2018). Sob tal perspectiva, Alves (2018) apresenta como questão fundamental a análise dos impactos financeiros nos processos de inclusão escolar e a importância do planejamento da oferta educacional como forma de subsidiar a disputa pelo fundo público para o financiamento da educaçáo básica em cada localidade. Com efeito, ressalta vicissitudes e controvérsias que ensejam as desigualdades de oportunidades educacionais no Brasil, em função da destinação, por parte do Estado, de uma parcela cada vez maior dos impostos arrecadados de forma injusta para o pagamento de juros a grandes grupos financeiros e fundos de investimento e de pensão. Esse panorama 
agrava-se ainda em razão de um histórico de metas não cumpridas na área social, em razão da falta de prioridade política, de diagnósticos insuficientes ou equivocados, da falta de mobilização e capacidade institucional e da ausência de previsão orçamentária correspondente às metas de serviços públicos para as classes pobres.

Diante desse quadro, Alves (2018) afirma que a garantia do direito à educação no Brasil requer um arranjo complexo de atores, instituiçóes, normas e recursos. Por isso, exige planejamento capaz de orientar as políticas públicas, em nível local e nacional, que considere a diversidade de contextos, a reestruturação do federalismo visando intensificar a colaboração entre os entes federados e equacionar problemas decorrentes das diferenças nas trajetórias e nas capacidades locais. Como contributos de um coletivo de pesquisadores do Laboratório de Dados Educacionais para diagnóstico de indicadores educacionais, Alves (2018) apresenta o desenvolvimento de uma plataforma on-line, com o simulador Custo Aluno Qualidade (SIMCAQ). O referido dispositivo proporciona aos sistemas de ensino subsídios para planejamento orçamentário das redes públicas de Educação Básica para a oferta de ensino em condiçóes de qualidade. Com efeito, proporciona tratamento de dados evidenciando distorçóes entre o financiamento efetivado pelos sistemas de ensino na oferta da educação pública e a prospecção de investimentos necessários para a garantia de uma educação de qualidade, de acordo com os parâmetros de qualidade estabelecidos pelo Custo Aluno-Qualidade Inicial (CAQi).

Cara (2018) retoma em sua exposição aspectos centrais do CAQi e do CAQ e os desafios de sua materialização em uma conjuntura marcada por retrocessos das políticas sociais. Apresenta um retrato retrospectivo da crise política e econômica enfrentada pelo governo brasileiro durante o Governo Dilma Rousseff e no período posterior ao seu impeachment, indicando um quadro grave de descontinuidades de conquistas sociais e acirramento da lógica mercantil. Ainda de acordo com Cara (2018), tal processo se substantiva na reforma do ensino médio, concretizando a visão de educação das fundaçóes empresariais; na elaboração da BNCC como estratégia homogeneizadora da educação para o mercado, somandose ao contexto de protagonismo das avaliaçóes de larga escala e instabilidades para a garantia do Fundo de Manutenção e Desenvolvimento da Educação Básica e de Valorização dos Profissionais da Educação (Fundeb), do CAQi e do CAQ.

O conferencista ressalta que, embora o CAQi seja uma proposta antiga nas políticas educacionais, a Campanha Nacional pelo Direito à Educação desenvolveu uma metodologia de cálculo que expressa requisitos mínimos para a garantia de uma educação de qualidade, como ponto de partida, conforme disposto no inciso IX do artigo 4o da LDB (BRASIL, 1996). Tal inciso assevera que os padrôes mínimos de qualidade estão relacionados a insumos mínimos indispensáveis aos processos de ensino-aprendizagem, tais como o piso salarial de magistério, a política nacional de carreira, a política de formação continuada; e insumos relacionados à infraestrutura, tais como equipamentos, biblioteca, laboratórios, quadras de es- 
portes cobertas, materiais didáticos, acesso à rede de esgoto, luz, acesso à internet banda larga. Contudo, é premente a criação de condições em escala progressiva para atingirmos patamares de qualidade, uma vez que o prazo preconizado pelo PNE para reajustes progressivos, visando ao alcance do valor do CAQ, expirou em 2017. Ainda segundo Cara (2018), as dificuldades para o desenvolvimento do CAQ têm sido recorrentes e desde a política de ajustes fiscais em 2015, do então Ministro Joaquim Levy, esses parâmetros de qualidade estáo comprometidos e as dificuldades para sua implementação se agudizam com a aprovação da Emenda Constitucional (EC) no 95. Destarte, é necessário buscar meios para revogar a referida Emenda, como também a reforma do ensino médio e a reforma trabalhista, as quais são apoiadas pelo mercado, com fins de investimento especulativo no Brasil, aviltando a consagração de direitos sociais, e, no caso específico do Novo Regime Fiscal, compromete o direito à educação.

Ximenes (2018), ao realizar um balanço dos 30 anos da promulgação da Constituição Federal (CF), destaca algumas tendências para o campo educacional, tais como a inovação do texto constitucional concernente à perspectiva integrada de direitos humanos. Com efeito, reconhece o direito à educação não somente como um direito de dimensão social e prestacional, por meio da intervenção do Estado na implementação de políticas públicas, mas também um direito à educação se substantiva por meio da garantia do pluralismo de concepções pedagógicas integrada aos direitos fundamentais, dispostos no artigo $6^{\circ}$ do texto constitucional. Além disso, destaca a legitimação do repasse de verbas públicas para instituiçôes privadas, com perspectivas de privatização e atuação subsidiária da União para a Educação Básica na realização no direito à educação.

Por outro lado, o conferencista desenvolve reflexóes sobre a crise orgânica do capitalismo e da crise da democracia liberal e seus efeitos nas lutas por reconfiguração do direito à educação no Brasil nesses 30 anos de promulgação da CF. Destarte, afirma que presenciamos um pacto constitucional assimétrico, mediante o interesse de manutenção de preservação de uma estrutura social e econômica para uma situaçáo que pode ser interpretada como estado de sítio fiscal, a partir da aprovação da EC no 95 . Ancorando-se no conceito convencional de Estado de Sítio - no qual se suspendem garantias constitucionais como habeas corpus e direito de ir e vir - , estabelece um paralelo metafórico sobre os efeitos da EC no 95, dado que as derivaçóes do referido dispositivo implicam também a suspensão ou o alijamento de garantias constitucionais relacionadas a direitos sociais como educação, saúde e seguridade.

Os paradigmas da lógica mercantil no campo educacional abordados pelos conferencistas brasileiros guardam conexôes com as análises desenvolvidas pelos pesquisadores lusitanos. Assim, Lima (2018), ao analisar as condiçóes objetivas de expansão e conservaçấo do capital, analisa as políticas educativas contemporâneas ensejadas pelas reformas gerencialistas da educação pública. Para tan- 
to, desenvolve o conceito de privatização lato sensu como modelo institucional de referência para a reforma da gestão educacional e as consequentes derivações desse processo, tais como as práticas meritocráticas e a crise da democracia nas escolas, resultando em uma educação alienante e desumanizada.

Afonso (2018) apresenta um quadro analítico a partir de dimensôes de natureza macrossocial mediante uma abordagem entre os determinantes da globalização/internacionalização da economia capitalista, a expansão do neoliberalismo e suas implicações na redefinição do papel dos Estados nacionais, alterando os pilares de regulação social da modernidade. De acordo com o conferencista, tendo como referência a realidade política e social de alguns países, a probabilidade de um excesso de regulação estatal para a radicalização da privatização e a reconfiguração de um Estado mínimo autoritário e coercitivo, implicará, necessariamente, um recuo profundo da emancipação, cuja reversão não deixará de exigir formas alternativas de resistência criativa e propositiva. Ressalta ainda que os novos acontecimentos ligados à crise econômica, às mudanças tecnológicas, às questóes ambientais e ecológicas, ao aumento das desigualdades (sociais e educacionais), às emigraçôes e aos movimentos de refugiados demandam a necessidade de criação de mecanismos democráticos de regulação.

Tendo como plano de fundo esse cenário mais amplo de oscilaçôes nos processos de construçóes e desconstruções das práticas democráticas do Estado contemporâneo, a conjuntura atual indica que a velha bandeira da democracia necessita ser recuperada e reerguida. Os efeitos disruptivos do atual cenário político brasileiro força-nos a pensar e problematizar os efeitos para as políticas sociais, para o Estado Democrático de Direito e para a dignidade da pessoa humana mediante o acesso aos direitos mais elementares. A ética do pensamento crítico-reflexivo presente nas abordagens dos conferencistas do VI SEB possibilita-nos problematizar nosso tempo, a refutar o papel de atores que cumprem o script definido a priori, e incita-nos a assumir nossa condição de sujeitos históricos, constituídos e constituintes de um processo social, autor e senhor da história.

\section{Notas}

1. Com a reforma trabalhista, os trabalhadores perderam mais de cem itens de seus tênues direitos previstos na Consolidação das Leis do Trabalho (CLT); enquanto isso, o Conselho Administrativo de Recursos Fiscais do Ministério da Fazenda (CARF) perdoou a dívida de R \$ 25 bilhôes do Itaú, por sonegação fiscal, em um momento em que o governo diz "não ter dinheiro em caixa, que precisa cortar investimentos sociais, privatizar, demitir, reformar a Previdência para garantir o pagamento de juros da dívida pública aos próprios bancos”. Informaçôes disponíveis em: <http://www.bancariosrio.org.br/.../39152-governo-temerperdoa>. Acesso em: 21 mar. 2019. 
2. Encontro Nacional de Educação; Encontro Nacional de Educação para Reforma Agrária; açóes e encontros estaduais dos Fóruns Estaduais de Educação; ações e encontros nacionais do Fórum Nacional de Educação; encontros e protestos dos movimentos estudantis, sindicais e entidades científicas.

\section{Referências}

AFONSO, A. J. Conferência III. Tendências regulatórias e os impactos na desigualdade educacional. In: SEMINÁRIO DE EDUCAÇÃO BRASILEIRA, Campinas, 4., 2018. Anais [...]. Campinas: CEDES, 2018. 1 arquivo mp3. (42 min).

AGUIAR, M. Â. Simpósio I: Reformas conservadoras e a "nova educação": orientaçôes hegemônicas em debate. In: SEMINÁRIO DE EDUCAÇÃO BRASILEIRA, Campinas, 4., 2018. Anais [...]. Campinas: CEDES, 2018. 1 arquivo mp3. (35 min).

ALVES, T. Conferência Simpósio II: Desenvolvimento social: desafios ao Estado e à educação. In: SEMINÁRIO DE EDUCAÇÃO BRASILEIRA, Campinas, 4., 2018. Anais [...]. Campinas: CEDES, 2018. 1 arquivo mp3. (34 min).

BRASIL. Lei de Diretrizes e Bases da Educação Nacional. Lei no 9.394, de 20 de dezembro de 1996.

CARA, D. Conferência Simpósio VII. Cenário atual: reafirmando lutas pela educação em uma sociedade desigual. In: SEMINÁRIO DE EDUCAÇÃO BRASILEIRA, Campinas, 4., 2018. Anais [...]. Campinas: CEDES, 2018. 1 arquivo mp3. (37 min).

CHAUÍ, M. Convite à filosofia. 13. ed. São Paulo: Ática, 1996.

DOURADO, L. F. Simpósio I: Reformas conservadoras e a "nova educação": orientações hegemônicas em debate. In: SEMINÁRIO DE EDUCAÇÃO BRASILEIRA, Campinas, 4., 2018. Anais [...]. Campinas: CEDES, 2018. 1 arquivo mp3. (36 min).

FREITAS, L.C. Palestra. Simpósio VI. Humanização e Mercantilização: tensôes na organização escolar e na formação do profissional da educação. In: SEMINÁRIO DE EDUCAÇÃO BRASILEIRA, Campinas, 4., 2018. Anais [...]. Campinas: CEDES, 2018. 1 arquivo $\mathrm{mp3}$. (34 $\mathrm{min}$ ).

KREIN, J. D. Palestra. Simpósio III. As recentes transformaçóes no mundo do trabalho e suas consequências para o campo da educação. In: SEMINÁRIO DE EDUCAÇÃO BRASILEIRA, Campinas, 4., 2018. Anais [...]. Campinas: CEDES, 2018. 1 arquivo mp3. (29 min).

LEHER, R. Simpósio I: Reformas conservadoras e a "nova educação": orientaçóes hegemônicas em debate. In: SEMINÁRIO DE EDUCAÇÃO BRASILEIRA, Campinas, 4., 2018. Anais [...]. Campinas: CEDES, 2018. 1 arquivo mp3. (38 min).

LIMA, L. C. Palestra. Simpósio VI: Humanização e Mercantilização: tensóes na organização escolar e na formação do profissional da educação. In: SEMINÁRIO DE EDUCAÇÃO BRASILEIRA, Campinas, 4., 2018. Anais [...]. Campinas: CEDES, 2018. 1 arquivo $\mathrm{mp} 3$. (31 $\mathrm{min})$. 
LINHART, D. Palestra. Simpósio III: As recentes transformaçóes no mundo do trabalho e suas consequências para o campo da educação. In: SEMINÁRIO DE EDUCAÇÃO BRASILEIRA, Campinas, 4., 2018. Anais [...]. Campinas: CEDES, 2018. 1 arquivo mp3. (32 min).

MORAES, R. C. Conferência. O Cenário político econômico mundial. In: SEMINÁRIO DE EDUCAÇÃO BRASILEIRA, Campinas, 4., 2018. Anais [...]. Campinas: CEDES, 2018. 1 arquivo $\mathrm{mp3}$. (44 $\mathrm{min}$ ).

PARO, V. H. Palestra. Simpósio VI: Humanização e Mercantilização: tensóes na organização escolar e na formação do profissional da educação. In: SEMINÁRIO DE EDUCAÇĀO BRASILEIRA, Campinas, 4., 2018. Anais [...]. Campinas: CEDES, 2018. 1 arquivo $\mathrm{mp3}$. (31 $\mathrm{min})$.

POULANTZAS, N. O Estado, o poder, o socialismo. 2. ed. Rio de Janeiro: Graal, 1985.

XIMENES, S. Palestra. Simpósio VIII: Direito Humano à Educação e a "nova educação". In: SEMINÁRIO DE EDUCAÇÃO BRASILEIRA, Campinas, 4., 2018. Anais [...]. Campinas: CEDES, 2018. 1 arquivo $\mathrm{mp3}$. (37 min).

\section{SOBRE A AUTORA}

Maria Vieira Silva é doutora em Educação pela UNICAMP. Professora titular da Universidade Federal de Uberlândia, atuando no Curso de Pedagogia e no Programa de Pós-Graduaçáo em Educação (Mestrado e Doutorado) no âmbito da Linha de Pesquisa Estado, Políticas e Gestão em Educação. Coordenadora do Grupo de Pesquisa Polis, Políticas, Educação e Cidadania.

Recebido em 21 de maio de 2019.

Aceito em 24 de julho de 2019. 